\title{
WORKPLACE DESIGN AS A STRATEGIC RESOURCE-A QUALITATIVE STUDY
}

\author{
Yvonne Schmid, University of Regensburg, Germany
}

dx.doi.org/10.18374/IJSM-20-1.3

\begin{abstract}
In these times of increasing global competition among firms and advancing technological innovation at work, firm resources have become more important than ever before. Workplace design is affected greatly by these new technologies. In this paper I draw upon the research in the management literatureâ Especifically the Resource-Based Viewâ €to' discuss the prerequisites of workplace design that can be leveraged for a sustainable competitive advantage.Based on a qualitative approach with data from four cases, I develop a framework describing six interrelated characteristics of workplace design to enable sustainable competitive advantage: Value, Overlap with Firm Strategy, Inimitability, Complementarity, Versatility, and Expression.To align the complex resource bundle of workplace design with firm strategy and to ensure its potential benefits, management should consider these characteristics during planning and implementation of workplaces. Further research is needed to understand the relevance and individual impact of these characteristics in different industries or cultures and over time.
\end{abstract}

Keywords: Workplace Design; Resource Based View; Qualitative Research; Case Study Analysis; Strategy 